\title{
LETTERS
}

\section{Comorbidities, Treatment and Survival}

\author{
Michael Froehner, MD, Rainer Koch, PhD, and Manfred P. Wirth, MD
}

Department of Urology and Biometry and Medical Statistics, University Hospital "Carl Gustav Carus", Dresden University of Technology Dresden, Germany.

$\mathrm{J}$ Gen Intern Med 27(10):1240

DOI: $10.1007 / \mathrm{s} 11606-012-2140-3$

(C) Society of General Internal Medicine 2012

To the Editor:- We read with great interest the study by Chamie and coworkers analyzing the prognostic significance of comorbid diseases in a sample of 1,031 men diagnosed with non-metastatic prostate cancer between 1997 and 2004. ${ }^{1}$ The detailed data allowed a comparison with our radical prostatectomy data set $(2,205$ patients treated between 1992 and 2005, mean follow-up 8.9 years),

Table 1. Competing Mortality Rates After 10 Years, Stratified by the Presence of Comorbid Diseases and Age Groups. The Corresponding Figures from the Study by Chamie and Coworkers ${ }^{1}$ Are Given in Parentheses for Comparison. Competing (Non-Prostate Cancer) Mortality Was Determined by Competing Risk Analysis, Resulting in an Estimation of Cumulative Incidence Rates for the Different Correlated Risks ${ }^{2}$

\begin{tabular}{lccc}
\hline \hline Comorbidity & $\mathbf{5 5}+$ years & $\mathbf{6 5}+$ years & $\mathbf{7 5 +}$ years \\
\hline Lung disease*: & $17 \%$ (versus & $20 \%($ versus & No event $(\mathrm{n}=$ \\
& $31 \% * *[1])$ & $58 \% * *[1])$ & $5 ;$ versus \\
& & $84 \% * *[1])$ \\
Peripheral vascular & $36 \%$ (versus & $40 \%($ versus & No event $(\mathrm{n}=$ \\
disease: & $20 \%[1])$ & $41 \%[1])$ & $2 ;$ versus \\
& & & $70 \%[1])$ \\
$\begin{array}{l}\text { Diabetes without } \\
\text { end organ }\end{array}$ & $17 \%$ (versus & $21 \%($ versus & No event $(\mathrm{n}=$ \\
damage: & $16 \%[1])$ & $34 \%[1])$ & $1 ;$ versus \\
$\begin{array}{c}\text { Diabetes with end } \\
\text { organ damage: }\end{array}$ & $26 \%$ (versus & $29 \%($ versus & No event $(\mathrm{n}=$ \\
& $29 \%[1])$ & $54 \%[1])$ & $3 ;$ versus \\
& & & $83 \%[1])$ \\
\hline
\end{tabular}

*mainly obstructive, not stratified by degree of severity; **moderate or severe chronic obstructive lung disease. concerning the four comorbid conditions: lung disease, peripheral vascular disease and diabetes with or without end organ damage (Table 1). With the exception of peripheral vascular disease (affecting only $2 \%$ of patients in our sample), in men aged 65 years or older selected for radical prostatectomy, the 10 -year competing mortality rates were lower than in the unselected sample analyzed by Chamie and coworkers, ${ }^{1}$ and clearly below the $50 \%$ limit. Among the few men with one of the four comorbidities selected for radical prostatectomy at an age of 75 years or older, no competing mortality was observed until now, probably due to the particular strict selection in this very old subgroup. These differences illustrate that the filtering during primary treatment choice modulates the prognostic significance of comorbidity. Comorbid conditions that may appear as contraindications to curative treatment in unselected patients may no longer do so after passing the initial filtering. Clinicians should keep this effect in mind when they consider comorbid diseases during the treatment decision process in men with non-metastatic prostate cancer.

Corresponding Author: Michael Froehner, MD; Department of Urology and Biometry and Medical Statistics, University Hospital "Carl Gustav Carus", Dresden University of Technology, Fetscherstrasse 74, 01307 Dresden, Germany (e-mail: Michael.Froehner@uniklinikumdresden.de).

\section{REFERENCES}

1. Chamie K, Daskivich TJ, Kwan L, Labo J, Dash A, Greenfield S, et al. Comorbidities, treatment and ensuing survival in men with prostate cancer. J Gen Intern Med. 2011;27(5):492-499.

2. Pintilie M. Competing risks: a practical perspective. Chichester, England; Hoboken, NJ: John Wiley \& Sons, 2006, pp 195-207. 